TECHNICAL NOTES AND MANUALS

Revenue Administration: Short-Term Measures to Increase Customs Revenue in Low-Income and Fragile Countries

Gilles Montagnat-Rentier

Fiscal Affairs Department

I NTERNATIONAL MONETARY FUND 


\section{TECHNICAL NOTES AND MANUALS}

\section{Revenue Administration: Short-Term Measures to Increase Customs Revenue in Low-Income and Fragile Countries}

Gilles Montagnat-Rentier

Fiscal Affairs Department

I NTERNATIONAL MONETARY FUND 


\section{INTERNATIONAL MONETARY FUND}

Fiscal Affairs Department

\section{Revenue Administration: Short-Term Measures to Increase Customs Revenue in Low-Income and Fragile Countries}

Prepared by Gilles Montagnat-Rentier

Authorized for distribution by Michael Keen

March 2019

DISCLAIMER: The views expressed in this paper are those of the author(s) and do not necessarily represent the views of the IMF, its Executive Board, or IMF management.

\begin{tabular}{|ll|}
\hline JEL Classification Numbers: & H2O, H25, H26, H29 \\
\hline Keywords: & $\begin{array}{l}\text { Customs Administration; Revenue; Compliance; Taxes on } \\
\text { International Trade; Low-Income Countries; Fragile Countries }\end{array}$ \\
\hline Authors' E-Mail Address: & gmontagnatrentier@IMF.org \\
\hline
\end{tabular}

CInternational Monetary Fund. Not for Redistribution 


\section{TECHNICAL NOTES AND MANUALS}

\section{Revenue Administration: Short-Term}

Measures to Increase Customs Revenue

in Low-Income and Fragile Countries

Gilles Montagnat-Rentier ${ }^{1}$

This note discusses administrative measures that can be implemented by customs administrations of low-income and fragile countries in a short period (about a year) to improve traders' compliance and improve revenue collection. These suggested actions have been identified based on the experience acquired through the International Monetary Fund's (IMF) Fiscal Affairs Department's (FAD) technical assistance (TA), particularly the findings and recommendations of TA missions to sub-Saharan African countries.

Strengthening low-capacity customs administrations requires structural reforms to support the effective implementation of defined strategies. Developing core operational functions such as risk management, audit, investigation and intelligence are good examples of such reforms. Modernizing human resource management policies or achieving a fully automated environment in a customs administration are longer-term reform projects. Long-term reforms are not addressed here. The note focuses on targeted actions with a potential to increase trade revenue in the short term, and which can be taken without mobilizing large resources or engaging in a broad reorganization.

It is hoped that the suggestions in this note will help stakeholders, including country authorities, customs management, donors and TA partners, area departments of the IMF, FAD, and the IMF regional TA centers, identify, design, and implement short-term changes in customs administrations. If implemented effectively, these changes should contribute to a noticeable improvement of revenue performance.

1 The author is grateful to colleagues who commented on previous drafts of this technical note, including Katherine Baer, Kenneth Head, Michael Keen, Mario Mansour, Stephen Mendes, Janos Nagy, Azael Perez, and Philip Wood. 


\section{CONTENTS}

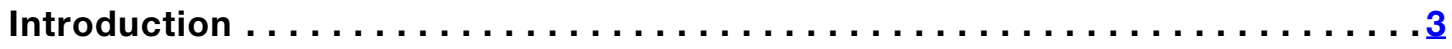

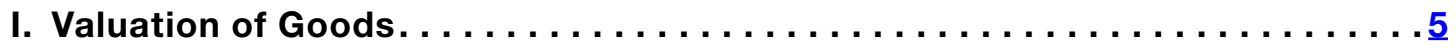

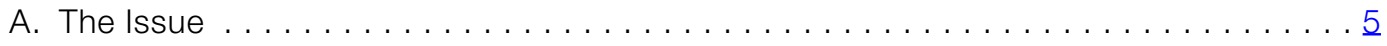

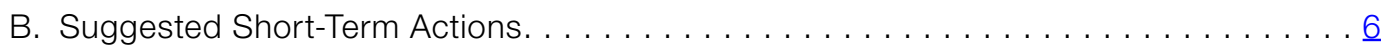

C. Practices That Are Not Recommended .......................

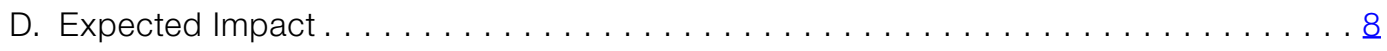

E. Notes for Further Medium-Term Actions $\ldots \ldots \ldots \ldots \ldots \ldots \ldots \ldots \ldots \ldots \ldots$

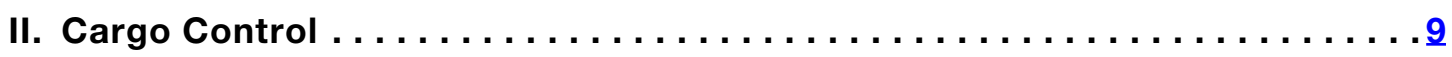

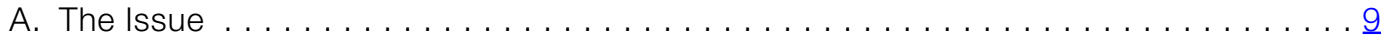

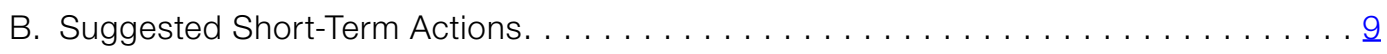

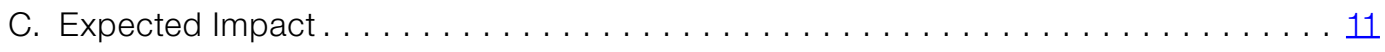

D. Notes for Further Medium-Term Actions . . . . . . . . . . . . . . . . . 11

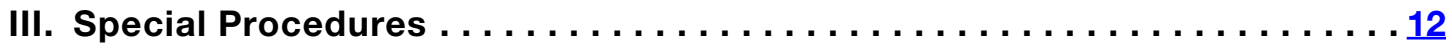

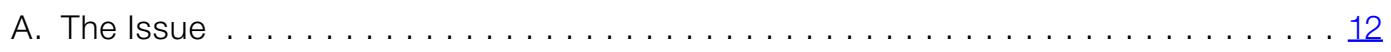

B. Suggested Short-Term Actions. . . . . . . . . . . . . . . . . . . 12

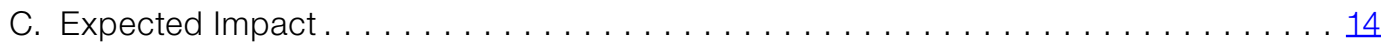

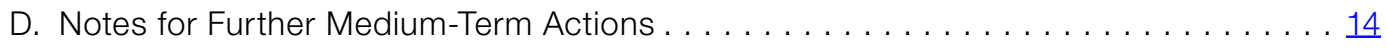

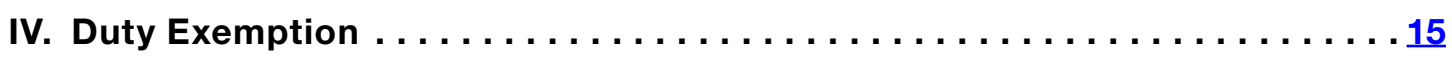

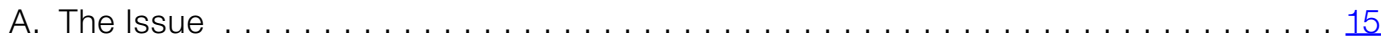

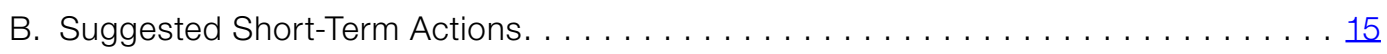

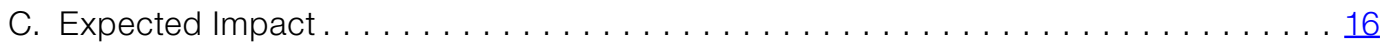

D. Notes for Further Medium-Term Actions . . . . . . . . . . . . . . . 17

V. Other Areas Requiring Particular Attention $\ldots \ldots \ldots \ldots \ldots \ldots \ldots \ldots$

A. Classification of Goods in the Tariff Nomenclature . . . . . . . . . . 18

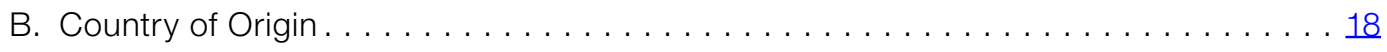

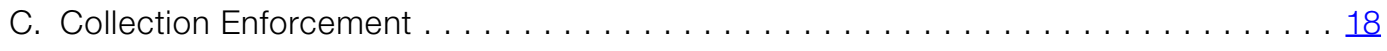

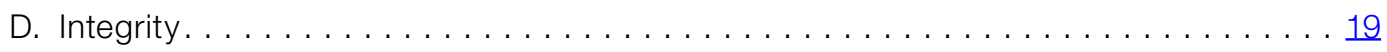

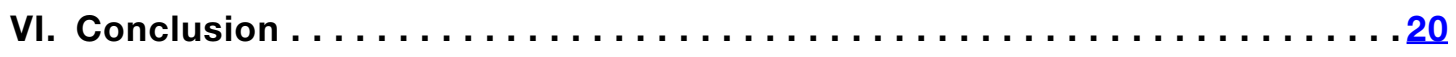

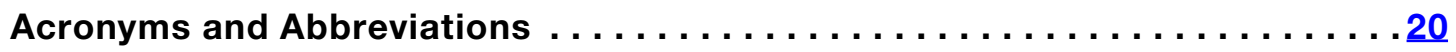

2 Technical Notes and Manuals 19/01 | 2019

CInternational Monetary Fund. Not for Redistribution 


\section{INTRODUCTION}

The mission of customs authorities around the world broadly falls into four categories: collecting duties and taxes on international trade in goods; applying tariff and trade policies, including trade facilitation measures; collecting trade statistics; and countering the import and export of noncompliant, dangerous, and illicit products. Through these activities, a customs administration pursues multiple objectives. These range from mobilizing government revenue to contributing to the business climate, preserving citizens' security and safety, producing economic and financial statistics, detecting illegal financial flows, and contributing to regional integration.

The subject that concerns us here is the collection of government revenues. This is a high priority for customs in low-income and fragile countries ${ }^{2}$ where taxes on international trade still account for a large share (often around 40 percent) of total tax revenue. Customs revenue in this note refers to customs duties and indirect taxes on import (value-added tax (VAT) and excise duties), which are collected by customs services in the same way as customs duties. Some other small levies on import and, in some countries, taxes on export, are also relevant.

Customs administration globally has been shaped by a number of treaties and conventions that influence both policy and practice and have ensured a progressively greater harmonization of customs operations towards common standards. ${ }^{3}$

The processes implemented by customs can be summarized as follows. Goods arriving in ports or leaving the country are presented to, and recorded by, the customs authorities. They are then cleared through customs, which means a customs procedure (import for consumption, temporary import, export, etc.) is requested by the declarant. Customs verifies that the declaration is correct, if necessary also by inspecting the goods, ensuring that the entry or exit obligations are fulfilled, and that correct duties and taxes (mainly customs duties, VAT, and excise duties) are paid. The duties and taxes collected depend on the value and/or quantity, the nature, and for customs duties, in some cases, the country of origin of a specific product.

Customs may carry out additional checks after it clears the goods, either by a desk review of documents furnished or by conducting a more detailed audit on site at an operator's premises. The purpose of these checks is to recover duties and taxes that may have been evaded at the time of declaration. Monitoring of goods after release is required for a number of customs procedures (e.g., transit to another country). A mobile customs preventive service is normally present at borders and around ports to ensure that goods are directed to customs clearance offices and to combat smuggling and other criminal activities. Investigation units are responsible for tackling fraud and trafficking throughout the entire customs territory, including prosecuting serious offences.

2 The definition of fragile states here follows that used in the recent IMF Executive Board Paper "Building Fiscal Capacity in Fragile States", published in June 2017. According to this classification, there are currently 43 fragile states, nearly half of which are in Sub-Saharan Africa. This paper differentiates low-income countries from countries in fragile situation for two reasons: fiscal institutions in countries in fragile situation tend to have weaker capacity than those in low-income countries; also, there are fragile states that are classified as middle-income countries.

3 The most important treaties and conventions are: (1) the Harmonized System-1988; (2) the WTO Agreement on Customs Value-1994; (3) the Arusha Declaration-2003; (4) the Revised Kyoto Convention-2006; (5) the World Customs Organization (WCO) Framework of Standards to Secure and Facilitate Global Trade (SAFE)_2006; and (6) the WTO Bali Trade Facilitation Agreement-2013.

\section{CInternational Monetary Fund. Not for Redistribution}


This note examines the actions that can increase customs revenues in low-income and fragile countries in the short term (about a year). In many of those countries, especially those in a postconflict or crisis situations and/or with a very low tax-to-GDP ratio, government revenue is critically needed for urgent social and development expenditures and sometimes to ensure the continuity of basic state functions. These suggested actions have been identified based on the experience acquired through FAD's TA, particularly the findings and recommendations of TA missions to sub-Saharan African countries. The measures examined are related to the assessment of the tax base (Section I. Valuation), control of goods under regular and special procedures (Sections II and III respectively), and the application of duty (Section IV. Exemptions). Section V discusses a few areas requiring special attention. The note also highlights further medium-term actions and identifies a few practices in areas covered in Sections I to IV that are not recommended. 


\section{VALUATION OF GOODS}

\section{A. The Issue}

The global standard to establish the customs value of imported commodities is Article VII of the 1994 General Agreement on Tariffs and Trade (GATT) and the World Trade Organization (WTO) Agreement on Implementation of this Article. These are referred to in the following paragraphs as "the Agreement.." The transactional value, i.e., the price paid or to be paid for the good, adjusted by a series of cost elements (e.g., insurance and freight) is the primary method to establish the customs value. Alternate valuation methods described in Articles 3 to 7 of the Agreement are to be used when the transaction value cannot be applied. There are three main situations where the transaction value cannot be applied (Box 1).

\section{BOX 1. Situations Where the Transaction Value Cannot be Applied for Customs Valuation of Imports}

There are three main situations where the transaction value cannot be applied, and alternate valuation methods are used instead:

1. The transaction value is rejected on the basis of failing one or more of the conditions of Article 1 of the Agreement (e.g., those applicable to related sellers and buyers).

2. The transaction value has been rejected following application of the procedures of WTO Decision 6.1, namely customs had doubts regarding the truth or accuracy of the declared value, which were conveyed to the importer, and customs' doubts remained after consultation was undertaken (see Box 2 below).

3. No sale has occurred (e.g., leased goods, gifts, goods transferred between branches, etc.).

Source: WCO Guide to Customs Valuation and Transfer Pricing, June 2015.

Implementation of the WTO rules is a challenging task for customs in low-income and fragile countries. Declared transactional values are often inaccurate, and many invoices are presented to customs that are not reliable. Customs must engage in large-scale control with limited resources and skills available. The outcome is generally not optimal. Ineffective verifications resulting in acceptance of inaccurate declared values, use of administrative values in contradiction with the Agreement, ${ }^{5}$ negotiations, and discretionary decisions are common. This situation leads to the undervaluation of goods, which in turn reduces revenues, results in the unfair treatment of importers, and creates economic distortions and governance issues.

4 References to the WTO rules below are applicable to WTO members.

5 Paragraph 2 of Annex III of the Agreement provides that developing country WTO members may make a reservation to retain an already-existing system of officially established values on a limited and transitional basis under such terms and conditions as may be agreed to by the Committee on Customs Valuation. 


\section{B. Suggested Short-Term Actions}

ACTION 1. Customs should collect and use comparative data to detect significant differences between declared values and average commodity prices. This is part of the risk assessment process. Customs administrations should set up an effective mechanism to collect data on prices of commodities commonly observed on the international market. Where a significant difference is found between a declared value and the indicative prices collected, the declaration should be deemed a risk and a verification should follow.

Customs agencies should assign a well-managed and motivated team of officers, with intelligence training, to gather price data and keep it in an updated database. The team could be set up as a "valuation support unit" positioned at customs headquarters. Price data should be collected through market surveys, online catalogs, queries addressed to foreign suppliers, exchanges of information with foreign customs administrations, and other techniques.

Customs agencies should then set up an internal procedure to match and compare data collected with declarations being received for same or similar goods. This procedure should be automated as soon as possible (depending on capacities, this may be a short-term or a medium-term action). Because of the large number of declarations, customs should first concentrate on high-value and high-risk goods.

ACTION 2. Customs should implement an effective, transparent, and WTO-compatible procedure to verify declared values when it has reason to doubt their accuracy or veracity. Observing that a declared value varies significantly from data available (Action 1) does not necessarily mean that it is wrong. It means that the declaration should be checked. To carry out the verification, customs officers must comply with the procedure agreed upon by WTO members (see Box 2). If correctly implemented, this procedure ensures effective and transparent verifications of values.

As a first step, this international practice could be introduced only in the main customs offices and, as previously mentioned, be focused on the high-value and high-risk goods because of resource and capacity limitations.

ACTION 3. Customs should enforce a scheme of progressive and proportionate penalties to raise compliance levels over time. The objective of the valuation control function should be to improve traders' compliance, not to repeatedly raise values to attract additional revenue. A clear sanctions policy should be developed to combat the systematic presentation of false or inaccurate invoices. The sanctions policy should differentiate between unintentional errors, deliberate incorrect application of valuation rules, and fraud, and between first and repeat offenders. Traders who use falsified documents or organized fraud schemes should be sanctioned heavily, including by prosecution, to deter the repetition of such behavior and to send a message to the trading community. Clearing agents participating in such schemes should be suspended or have their licenses revoked. 


\section{BOX 2. WTO Ministerial Decision 6.1 Regarding Cases Where Customs Administrations Have Reason to Doubt the Truth or Accuracy of the Declared Value \\ (Extract - The Articles mentioned are those of the Agreement)}

- When a declaration has been presented and where the customs administration has reason to doubt the truth or accuracy of the particulars of documents produced in support of this declaration, the customs administration may ask the importer to provide further explanation, including documents or other evidence, that the declared value represents the total amount actually paid or payable for the imported goods, adjusted in accordance with the provisions of Article 8.

- If, after receiving further information, or in the absence of a response, the customs administration still has reasonable doubts about the truth or accuracy of the declared value, it may, bearing in mind the provisions of Article 11, be deemed that the customs value of the imported goods cannot be determined under the provisions of Article 1.*

- Before taking a final decision, the customs administration shall communicate to the importer, in writing if requested, its grounds for doubting the truth or accuracy of the particulars or documents produced and the importer shall be given a reasonable opportunity to respond.

- When a final decision is made, the customs administration shall communicate to the importer in writing its decision and the grounds therefor.

- It is entirely appropriate in applying the Agreement for one Member to assist another Member on mutually agreed terms.

* In that case, the customs value is determined through another authorized valuation method. These alternative methods must be used in the order prescribed by the Agreement.

\section{Practices That Are Not Recommended}

Country authorities have tried to address the valuation issue by contracting companies that pre-inspect consignments in the country of export (also called pre-shipment inspection) and issue an opinion on their value. However, pre-shipment inspection (and its variant, destination inspection) has had limited effect on improving valuation control, particularly on raising compliance levels, for conceptual and practical reasons. ${ }^{6}$ If private services are sought for the valuation of imports, they should focus on supporting customs by providing additional information on request, such as price data. The WTO Trade Facilitation Agreement rejects the use of pre-inspection for valuation and tariff classification purposes.

For effectiveness and compliance with the WTO's requirements, customs should compile both external and internal data. Data from external sources is critical for Action 1 (The detection of possible irregularities or fraud). Internal data is necessary for Action 2 (The application of alternate valuation methods), where there is a requirement for recent and thoroughly verified imports of identical or similar goods.

6 These include: duplicated and uncoordinated processes, opinions provided by the company that customs does not use, questionable recommended values, poor oversight by customs management, absence of reconciliation of customs' and the company's data, and importantly, flawed design of the contracts. See Dequiedt V., A.M. Geourjon and G. Rota-Graziosi, Mutual Supervision in Preshipment Inspection Programs, Journal of Development Economics 99 (2012), p. 282-291. 


\section{Expected Impact}

There is no easy assessment of the impact of import valuation noncompliance in a country. By its nature, each transaction is a particular valuation case for customs. However, recent studies have used mirror statistics (export data to one country compared to the recorded imports of this country) to determine by sector or type of good whether there is a valuation gap and how it could be explained. ${ }^{7}$ Mirror statistics should be used with caution because asymmetries can result for various reasons other than import misdeclaration. Confirming or discarding misdeclaration therefore requires careful analysis of administrative practices and/or audit. That said, these studies can provide very useful insights to the authorities and to customs in an area where data is scarce.

The outcome of the proper application of WTO rules may in some cases be a reduced value. Imports may have been overvalued by the declarant or through the application of administrative values by customs. ${ }^{8}$ Importers may declare a customs value that is higher than the transaction value to increase charges in order to reduce their domestic taxes or to illegally export foreign exchange. Recent studies provide evidence of tax-motivated transfer pricing taking place in trade in real goods. ${ }^{9}$

\section{E. Notes for Further Medium-Term Actions}

The next steps in strengthening customs valuation of goods should include the following actions:

1. Customs should collect further information to be able to reject the transaction value in cases 1) and 3) described in Box 1, particularly to determine if companies' relationships have influenced the price of the goods and whether this could lead to rejection of the transaction value. Customs should collect information on existing relationships between importers in the country and exporters abroad. This should be done in collaboration with the tax administration as the information will also be useful to control the tax implications of transfer pricing.

2. Customs should use data for strategic risk analysis regarding valuation. In this regard, as mentioned in Section D above, mirror statistics can be used to carry out assessments of valuation/revenue gaps by sector and by type of commodities.

3. Valuation control should fit into the broader customs control strategy, which should differentiate actions before and after customs clearance. Verifications before clearance should concentrate on simple cases and importers from the informal sector or the shadow economy (as they may disappear or be difficult to locate after the release of goods). More complex issues should be dealt with through post-clearance audits.

7 See Cariolle J., C. Chalendard, A.-M. Geourjon and B. Laporte, Décloisonner l'analyse des données pour appuyer la modernisation des douanes: une illustration à partir du Gabon, FERDI Working Paper 173, November 2016; and Chalendard C., G. Raballand and A. Rakotoarisoa, The Use of Detailed Statistical Data in Customs ReformThe Case of Madagascar, World Bank Group Policy Research Working Paper 7625, April 2016.

8 In this case, it would be important for the authorities to consider coordinated tax policy or administration measures in other areas than customs valuation.

9 See Liu L., T. Schmidt-Eisenlohr, and D. Guo, International Transfer Pricing and Tax Avoidance: Evidence from Linked Trade-Tax Statistics in the UK, Oxford University Center for Business Taxation Working Paper 17/15, July 2017. 


\section{CARGO CONTROL}

\section{A. The Issue}

Cargo control in entry/exit points is generally far from optimal in low-income and fragile countries because of weaknesses in the management and operation of customs procedures. Revenues are often evaded because procedures are only partially automated, use of existing computer systems is ineffective, there are procedures that are incompatible with computerization, customs officers do not take appropriate action as regards incidents and against infractions, and customs managers do not monitor operations. Ideally, cargo reporting and clearance procedures should be electronic and paperless, with the data available from computerized systems routinely used to inform the actions of customs officers. This objective requires medium- to long-term reforms. However, Section B below outlines a number of helpful measures that can be implemented in the short-term, before modernization of procedures is finalized. Indeed, for customs procedures that are already computerized, removing the corresponding manual procedures which remain in parallel without good reason and requiring officers to apply properly the instructions of the administration would not encounter any technical obstacles.

\section{B. Suggested Short-Term Actions}

ACTION 1. Customs should require cargo manifests in electronic format only and ensure the integrity of the data. Customs should be certain about the quantity and type of goods arriving in the country. Discharge of cargo manifests should be automated to prevent subsequent errors or fraud. Customs should therefore receive the cargo manifests electronically, presented in an international standard format, ${ }^{10}$ preferably directly from the shipping line and if not from the shipping line's agent. Technical specifications should ensure that manifests cannot be modified. Should differences arise between the manifest and the goods unloaded in ports, the manifest should be amended under customs control and within a limited time span, e.g., 48 hours. Customs should review the quality of manifest data provided and impose penalties for non-compliance.

\section{ACTION 2. Eliminate manual procedures that are associated with existing computerized} procedures. The actual or alleged urgency of certain imports is often cited as a reason for reintroducing manual procedures that bypass the customs IT system (e.g., "direct removal" procedures). The declarations are then regularized (i.e., entered into the computer system) at a later date or not regularized at all. Duty assessment is made without sufficient verification. Sometimes importers are allowed to pay the duties after the release of consignments without payment or a security. This can lead to the build-up of considerable arrears. As a result of resistance to change, frequent failures of the information technology (IT) system and corrupt practices, customs personnel record their interventions in the paper copy of declarations instead of in the system. In some cases, despite the fact that electronic entry of manifests is already in force, officers continue to demand and make use of hard copies of manifests. This working practice often results in the IT systems not being correctly updated.

10 The CUSCAR message (CUStoms CARgo report message) is an international EDIFACT message that, in principle, is used to send a customs manifest to Customs. 
Eliminating procedures that take place outside the computer system ${ }^{11}$ is justified on two levels: to prevent revenue losses, and to have exhaustive data to detect and deal with non-compliant transactions. Customs controls cannot be carried out without reliable and comprehensive data. It is essential that electronic manifests be automatically discharged by the validation of the electronic declarations. The system can produce the status of incidents: uncleared manifests and unfinished declarations (see Action 3). No non-automated intermediate steps should disrupt this process, e.g., monitoring of container freight stations and other customs areas left out of the customs IT system.

ACTION 3. Ensure that customs personnel promptly process any pending operations in accordance with agreed procedures. The heads of units and customs management should regularly extract from the computer system the reports of unresolved operations, including the list of unacquitted manifest lines and unfinished declarations (unpaid declarations, release note not issued, goods not removed from the customs areas, etc.). They should instruct their staff to use the measures in the Customs Code to regularize these operations (location of goods, auctions, collection of duties due, enforcement of penalties, search and prosecution of fraud, etc.) and check that these tasks have been completed.

ACTION 4. Automate all taxation rules in the "Integrated Tariff" tables of the customs IT system. The aim here is not to allow customs declarants or customs staff to carry out calculations. An "automated integrated tariff" is already operational in most customs administrations. The issue is whether all the rules are in the module of the system and kept up-to-date according to a verified protocol. It is particularly important that the customs IT system have access to an updated taxpayer identification number (TIN) database maintained by the tax administration. Ideally the systems/ databases of the customs and tax administrations should be linked to permit the automated verification of the validity of the TIN used in the declaration, to the extent possible.

ACTION 5. Implement specific measures to control transactions of informal sector operators. Imports of miscellaneous items in bulk containers, by several importers together from the informal sector, is a common and growing phenomenon in low-income and fragile countries. By "informal sector importers," what is meant here is operators who are not registered in the taxpayer register, or, if registered by the tax administration, do not usually comply with their filing and payment obligations. In addition, the TIN indicated in the customs declaration may be that of a third party. A common risk with such imports is that the list of goods and their tariff classification and value are inaccurately reported in the customs declarations. To protect revenues and curb this practice, Customs should require mandatory presentation of the packing lists, carry out extensive physical inspections of such consignments, and verify the accuracy of the TINs indicated in the customs declarations. Such actions may require additional resources, but they should not present any significant technical challenges.

11 Customs administrations in developing countries are now equipped with an IT system for the processing of imports and exports, at least a basic one to capture declarations, assess duty and tax, and record payments. 


\section{Expected Impact}

Estimating revenue lost from failures in cargo reporting and clearance procedures is not easy. An apparent "normal" processing of imports and exports may hide serious issues. ${ }^{12}$ Therefore, an in-depth review of unacquitted operations ${ }^{13}$ in the IT system may be a starting point to assess the magnitude of the problem and determine the priority remedial actions. Preferably, a regular system review by the internal audit office should be undertaken.

\section{Notes for Further Medium-Term Actions}

The following structural reforms are essential to ensure effective cargo control by customs.

They should be part of any modernization program.

1. The full automation of customs procedures so that every step is acquitted automatically by the subsequent one.

2. The implementation of paperless procedures. This is not only a very important simplification for the trade community but also provides assurance that customs officers' interventions are recorded in the system and can be monitored and audited.

3. Protection of the customs IT systems and data against intrusion and manipulation should be robust and effective. Internal and external audit programs should be established to address this risk

12 As a recent example, in the main port of an East African country, it was discovered that several hundred containers of imported goods had been removed without customs declarations and payments.

13 A customs declaration or operation is "acquitted" when the step that must follow is settled to the satisfaction of Customs. For example, submission of the manifest (declaration for cargo reporting) shall be followed by the customs declaration (declaration for clearance) within a certain time frame. 


\section{SPECIAL PROCEDURES}

\section{A. The Issue}

Internationally customs can apply procedures to suspend duty and tax for a period of time, until the goods are re-exported or cleared for domestic consumption. The customs transit procedure allows goods to be moved from a point of entry or departure in a country to a point of destination in another country (international transit) or in some cases the same country. A series of other customs procedures are available to traders to store, use, or transform goods where duty and tax have been suspended but that remain under customs' supervision. The most common procedures for this are bonded warehousing and temporary admission. Many countries also operate so-called "free zones (FZs)" or "economic zones" where duty and taxes do not apply.

With all these procedures there is a high risk of goods being diverted to the domestic market without payment of duty and taxes. While tight and constant control should be the response, the customs administrations of low-income and fragile countries are often faced with various practical issues that prevent them from effectively monitoring post-release operations. Weak follow-up capacity is a shared feature among these administrations and is a common reason for revenue losses.

\section{B. Suggested Short-Term Actions}

ACTION 1. Ensure physical security of transit cargo. The principal priority to protect revenue under customs transit procedures should be the physical security of cargo loads during transport. This requires that goods be transported in sealed containers from the point of departure to the point of arrival, without being opened during the journey.

Customs administrations should limit to the minimum authorizations for the unloading in seaports of containerized goods declared for transit before their reloading in bulk on trucks that cannot be sealed. If the high costs of containerized transport in the region are an issue, e.g., because of the requirement for additional insurance payments to make sure the container is returned, then the authorities and the trade community should work together to reduce these costs and to put in place appropriate control measures.

Customs should require containers and closed trailers to be securely locked. A recommended technological solution is container/trailer locks with a tracking device that instantly reports opening attempts to a customs command post. Customs should establish a national center that can undertake a realtime monitoring of transit cargo across the country, based on the use of these devices. A customs mobile team should be available to intervene on-site immediately when an incident is reported. These measures require resource mobilization and training. However, authorities in countries where customs transit procedures are widely used should be aware that this specific investment in resources and capacity building is worthwhile, given the revenues involved. 
These measures will mitigate the risks of dumping of goods, theft, and inadequate verification or false reporting of the presence of goods by customs officers located at border posts. In addition, customs should require a bond guarantee for all transit operations, and the authorities should make sure that customs can easily realize the bonds issued by banks and insurance companies. ${ }^{14}$

\section{ACTION 2. Report undischarged transit operations daily. Recover the duty and taxes due} without delay. This action should be comprised of several steps:

- Where there are no effective communications between customs offices and remote border posts, information on whether trucks and cargo have or have not exited the country is often not received in a timely manner (or sometimes never received). To address this risk, a small number of strategic border posts should be connected to the customs IT system as soon as possible. This will enable the departure offices, or a central customs transit office, to monitor transit operations and address any incidents.

- The number of days granted to cross the country and the itinerary should be specified and recorded in the IT system. This will allow the system to generate an immediate report of undischarged operations.

- The customs IT system should automatically release notifications of payment of duty related to undischarged operations.

- The notification of payment of duty should be addressed to the person who has taken responsibility for the transit operations. A common mistake that customs makes is to launch investigations (which may take months or more) before attempting to recover the suspended revenue. Both tasks are critical (recovery of duty and repression of fraud) but should be undertaken separately.

ACTION 3. Enforce the rules applicable to the approval and duration of duty relief procedures. In many low-income and fragile countries, there is an excessive use of bonded warehouses and temporary admissions as a form of, or substitute for, duty exemptions. Lax authorizations and long stays of goods under these regimes facilitate abuse and fraud. Bonded warehousing and temporary admission should be authorized only when the applicant demonstrates a clear economic or business justification for needing these procedures. The list of authorized operations and manipulation of goods should be specified and controlled. Time limits for goods to remain under these procedures should be aligned to international standards and enforced (by re-exportation or declaration for home consumption, if not by auction or taxation of overstayed goods).

\section{ACTION 4. Reconcile customs declaration data and physical inventory reports on a regular} basis. Customs control of bonded warehouses and temporary admissions require: (1) declarations to be made in the customs IT system and effective checks of inputs and outputs; (2) periodic and comprehensive inventories of the goods under the regime; (3) action taken by customs to recover duty on deficit or excess goods; and (4) imposing sanctions against noncompliance, including the cancellation of authorizations for traders involved in fraud and serious abuse.

\footnotetext{
14 The guarantor commits to settle duties and taxes due when the transit operation is not cleared and the person responsible for this operation does not pay. In many developing countries, customs report that the guarantor does not respect this commitment.
} 
ACTION 5. Ensure physical security of Free Zones. The FZ operators must be required to maintain a secure perimeter with security deficiencies such as breaches in walls and fences being brought to their attention promptly. Customs management should follow up to make sure that repairs have been done. Where possible, customs should insist on the use of technology such as closed-circuit television (CCTV) that customs can access and use to monitor perimeter security and access.

\section{Expected Impact}

The revenue impact depends on the magnitude of the problem in each country. Poorly monitored transit procedures (e.g., customs unable to provide instant reports), a high number of bonded warehouses in relation to the country's economy (especially for heavily taxed goods such as alcohol and tobacco) or temporary admissions that are accepted indefinitely, are typical signs of serious dysfunctions and likely substantial revenue loss.

\section{Notes for Further Medium-Term Actions}

The following additional actions are advised to better monitor special procedures:

1. As a longer-term objective, international transit procedures should rely on the electronic exchange of data between the respective customs authorities. The destination office should report completion of the transit of goods to the office at the original point of entry. Border posts on the route should note the crossing of the truck/container. This requires an interconnection of national customs IT systems, which overall has not progressed much in developing countries. ${ }^{15}$

2. The FZ activities are often challenging for customs administrations. Given the revenue at stake, governments should retain customs control of the FZ with the customs authority rather than with any separate FZ agency. Such a separation of responsibilities will avoid any potential conflicts of interest. The FZ should not be deemed to be outside the customs territory but should be considered as a part of the customs territory benefiting from special treatment. Customs should be able to access in real time the FZ's inventory control system, which should comply with a standard predefined by the customs authority.

3. Control of special procedures for transformation of goods presents specific difficulties. Training of officers in the understanding of specific high-risk industrial processes is needed.

15 There are exceptions. The East African Community (EAC) members, for example, have made good progress as regards interconnection, along with implementation of the EAC Single Customs Territory procedures. 


\section{DUTY EXEMPTION}

\section{A. The Issue}

The proliferation of import duty and tax exemptions is particularly common in low-income and fragile countries. This often means that some traders can import goods duty-free or at a lower rate, while others must make up the loss and carry a heavier duty burden. These measures are a major drain on government revenue, and often have a negative impact on competitiveness and broader goals of societal fairness. Broad tax policy reforms would be needed—and have been recommended by FAD—to set clear principles for the exemptions regime, putting into balance the negative revenue impact versus any social and economic benefits, and to rescind unnecessary or counterproductive exemptions. ${ }^{16}$

\section{Strengthening administrative control of such exemptions is critical to combat their abuse.} The process of administering exemptions in low-income and fragile countries can be broadly described as follows: (1) various laws, agreements between the government and certain entities, and regulations grant customs duty or tax (e.g., import VAT) exemptions; (2) on this basis, traders request authorization from the authorities before their planned imports to confirm entitlement to an exemption; ${ }^{17}$ (3) upon arrival of goods in ports, customs declarations are accompanied by the authorization certificate; (4) after verification that the goods declared match the description of items covered by the certificate, customs releases them without payment (or with reduced taxation in the case of partial exemption); and (5) exempted goods must be used or consumed according to the conditions set forth in the law, agreements, and regulations. These steps generally present weaknesses and loopholes, such as imprecise definition of exempted goods, beneficiaries or conditions for exemption, or insufficient customs control, which are taken advantage of by non-compliant traders.

\section{B. Suggested Short-Term Actions}

ACTION 1. Define exemption rights with precision, and publish them. Import exemptions are generally loosely defined. They cover a wide range of goods and are granted to numerous categories of persons. The first precaution against abuse is to define precisely the authorized beneficiaries, characteristics of exempted commodities, and specific obligations relating to the use of the goods after customs release. Customs often complains about vague laws and regulations without being proactive in proposing remedial actions to the judiciary and government policy makers. The definition of exemptions should not be left only to other government ministries and agencies. The Ministry of Finance and customs should take the initiative to draft secondary legislation/regulations to improve the definition of exemptions and submit the proposals for approval. For certain exemptions, regulations should set annual quotas. ${ }^{18}$ Normally, the law should authorize the Minister of Finance or the Director General of Customs to adopt directives for the administration of exemptions.

\footnotetext{
16 See Options for Low Income Countries' Effective and Efficient Use of Tax Incentives for Investment, A Report to the G-20 Development Working Group by the IMF, OECD, UN and World Bank, October 2015.

17 "Authorities" generally means the minister of finance or more often the director general of customs, depending on the country or the type of exemption. In some countries, another ministry or agency can authorize exemptions without the ministry of finance's approval: this is a bad practice, because the ministries and technical agencies may not pay enough attention to the budgetary implications of exemptions and because the finance ministry should anticipate, record and control the total cost of these measures.

18 For example, exemption of fraud-sensitive products such as fuels for motor vehicles.
} 
If not, a possibility remains for the head of the customs to take legal-consistent instructions to clarify or specify the rights to the exemption and procedure to be followed to benefit from it. All exemption schemes, regulations and directives should be published in the gazettes.

ACTION 2. Assign numerical identification to the exemption criteria. Integrate these codes into the customs IT system for automated processing. Exempted commodities should always be identified by the numerical codes of the customs tariff nomenclature-i.e., the Harmonized System (HS), subdivided as needed. Categories of beneficiaries should be defined with reference to objective and verifiable criteria, including mention of the legal status whenever possible, e.g., "governmentapproved non-governmental organizations." Customs should be able to access the TINs of beneficiaries, including potential beneficiaries. This information should be integrated into the customs IT system, and importers should be required to report their TIN in their applications for exemption and also on their customs declarations.

ACTION 3. Monitor the importers' obligations after customs release. This is a critical and overlooked step in the process. FAD's TA missions have noted that customs administrations generally verify exempted goods before they are cleared for entry. However, this verification is only part of the control. Virtually all import exemptions are subject to restrictions regarding the use of the exempted goods. ${ }^{19}$ Despite these obligations, customs undertake few audit and enforcement actions after clearance. Customs should seek evidence of the correct use of the exempted imports through desk reviews of further documentation and a field audit to verify compliance at importers' premises. When the Customs code does not provide the necessary powers to customs officers to visit importers' premises to conduct stock reconciliations, it should be revised.

\section{ACTION 4. Customs should report revenue foregone and administrative challenges to the} authorities and suggest improvements. For informed policy decision making it is important that the Minister of Finance be aware of the revenue cost of exemptions for the fiscal year, by exemption scheme (legal basis), economic sector, and category of beneficiaries. It is important that a consistent set of data on tax expenditures be shared among the administrations and the authorities. The minister should also be aware of the issues pertaining to the administration of these measures. For that purpose, customs administrations should release to their authorities accurate and comprehensive reports, including any irregularities identified and, where appropriate, proposals for improvements.

\section{Expected Impact}

The right policy decisions as mentioned in Section A would clearly be the most effective way to reduce the revenue foregone from exemptions. Nonetheless, the administrative measures proposed, beginning with the precise definition of exempted commodities and exemption conditions, can have a significant impact. It is not unusual in sub-Saharan African countries for the revenue foregone from exemptions to account for about a third of potential revenue collectible by customs. ${ }^{20}$ In the Caribbean this often exceeds 20 percent of potential customs revenue. ${ }^{21}$ The limited customs audit coverage and

19 For example, duty-free cement destined for the construction of a public infrastructure project should not be diverted to build private homes.

20 See Zake J. O., Customs Administration Reform and Modernization in Anglophone Africa - Early 1990s to Mid-2010, IMF Working Paper, August 2011; and Montagnat-Rentier G. and G. Parent, Customs Administration Reform and Modernization in Francophone Sub-Saharan Africa, 1995-2010, IMF Working Paper, October 2012.

21 See Chai J. and R. Goyal, Tax Concessions and Foreign Direct Investment in the Eastern Caribbean Currency Union, IMF Working Paper, November 2008. 
results observed, and anecdotal evidence of organized fraud (e.g., unauthorized transfers of exemption authorizations, sudden increases in imports of certain commodities) suggest abuse of exemptions on a large scale. It should be noted that a proportion of the percentages mentioned above corresponds to uncollected VAT. If the imports had generated tax a substantial proportion of it would have been credited. Nevertheless, the risk for diversion of VAT-exempt goods remains important.

\section{Notes for Further Medium-Term Actions}

Additional medium-term actions would further strengthen exemption control:

1. It is recommended that an IT module be utilized to process exemption authorizations, and that it should interface with the IT system used for customs clearance. This may limit fraud attached to false documentation, speed up formalities, and help the authorities prepare for a trade single window. This action should be part of the customs IT strategy and supported by technical assistance.

2. To facilitate the monitoring of exemptions, Customs Codes may be revised to classify any exemption scheme as a type of special relief procedure (see Section III). Under this regime, traders and customs officers would have to comply with specific legal obligations after the release of goods. ${ }^{22}$

3. It would be a reasonable and effective measure to exclude persons/legal entities that have been involved in customs fraud from any exemption privileges.

4. Actions in Section B and above should be seen as a prelude to the government's implementation of a tax expenditure exercise. All tax and customs exemptions would be identified, baselines determined, costs estimated, and an annual report made to the Parliament as part of the budget process. Benefits and costs of exemptions should be published to show the entire population whether existing exemptions are useful for the economy and society or not.

5. To ensure effectiveness of implementation and promote transparency, the entire exemptions regime, including authorizations, should be subject to an annual audit and scrutiny by a national body such as the National Audit Office or the Public Accounts Committee, and the outcome published.

6. Positive and especially high tariff rates on capital and intermediate goods often explain the pressure placed on the authorities to provide customs duty exemptions. Consideration could be given to introduce a zero or very low rate for these goods, to resolve this issue (this solution is, however, simple for goods that are only or predominantly used as inputs, but less straightforward for goods that could be both inputs or consumption goods).

22 The European Union has implemented this measure and the Central African Economic and Monetary Community (CEMAC) is considering the introduction of specific provisions for exemption control in its Customs code. 


\section{OTHER AREAS REQUIRING PARTICULAR ATTENTION}

\section{A. Classification of Goods in the Tariff Nomenclature}

BACKGROUND AND ISSUE. Imported and exported goods are classified worldwide in the Harmonized Commodity Description and Coding System, a general nomenclature referred to as the "Harmonized System" or "HS." Many believe that classification in the HS is straightforward-but while many commodities have a designated classification, many more do not. They are classified through the application of various HS rules. Although tariff rates are relatively high in low-income and fragile countries, verification of classification is often left to untrained employees in local offices. ${ }^{23}$ There is a lack of specialized officers and risk assessment in this area.

SUGGESTED SHORT-TERM ACTIONS. To counter undetected misuse of lower-rate tariff bands, customs should develop advanced tariff classification rulings. Not only should traders be encouraged to request such rulings, but customs should proactively publish administrative tariff classification decisions for any goods presenting classification challenges. Classification should be reviewed by specialists at the central office, with local staff's role limited to checking conformity of the declared goods with the description in the ruling.

\section{B. Country of Origin}

BACKGROUND AND ISSUE. From a revenue perspective, control of the country of origin is important where the importer may request reduced duty rates for goods that fulfill certain "preferential" origin criteria. These specific rates and rules of origin are generally established by a preferential agreement concluded by the importing country (or the customs union it belongs to) with another country or region ${ }^{24}$ (e.g., the Economic Partnership Agreements concluded by African countries or group of countries with the European Union). Control of origin, including preferential origin that gives right to lower duty, has not been a focus of customs control in many low-income and fragile countries. Customs' capacity to detect origin fraud remains limited in these countries.

SUGGESTED SHORT-TERM ACTIONS. Customs should start by setting up a national team ${ }^{25}$ to study trends and variations of origin of imports, train officers in field offices to detect false or inapplicable preferential origin documentation and coordinate the requests to export countries for verifying certificates of origin. Customs officers, for their part, should be instructed to be mindful of indicators of origin when conducting examinations and act when discrepancies are identified.

\section{Collection Enforcement}

BACKGROUND AND ISSUE. Customs enforcement actions have revenue and deterrence effects only if evaded duties and penalties are fully recovered. This is not always the case in low-income and fragile countries, for at least two reasons. First, customs administrations' capacity to enforce revenue collection is generally low. Customs services are generally accustomed to the regular clearance process,

23 In line with Article 4 of the WTO Trade Facilitation Agreement, classification rulings, like other administrative decisions issued by customs, should be open to appeal if the trader disagrees with customs.

24 Unilateral tariff preferences exist but are usually granted by higher income countries to developing ones.

25 In customs agencies, the teams in charge of classification, valuation and origin issues are often placed together in a specialized unit commonly known as CVO. 
whereby goods are kept under customs control until duties are paid; customs have not invested in resources to recover evaded duties discovered after they are released from customs (e.g., through postclearance audit). Second, the rules that are applicable to the handling of customs debts (again, those not resulting from the regular clearance process) are usually vague or nonexistent. Follow-up action to recover the money is usually very poor in this context.

SUGGESTED SHORT-TERM ACTIONS. Where needed, the government should revise the customs regulations to establish the procedures for the notification, recording in accounts, and payment of the various types of customs debts that occur after or outside the customs clearance process. These rules should then be automated in the customs IT system. Simple collection cases can be left to customs offices. By contrast, a specialized enforcement collection unit (possibly out of the customs agency, e.g., a domestic tax enforcement unit) should handle complex or high-risk cases.

\section{Integrity}

BACKGROUND AND ISSUE. Action by customs to secure and enhance revenue will be adversely affected by shortcomings regarding integrity. There is a strong perception in most developing countries that corruption is common in the customs agency, ${ }^{26}$ a situation that exists, because, among other things, customs officers hold significant power over valuable commodities. ${ }^{27}$ This situation is attributable to a combination of factors including ambiguous or incomplete laws, regulations and procedures; inadequate management control and oversight of officers; insufficient audit of transactions and procedures; conflicts of interest; and very low salary levels. Customs must recognize that the problem exists and take decisive steps to address it. This requires a long-term pro-integrity strategy inspired by the Arusha Declaration, including such measures as education campaigns, a program of systems audit, and requiring customs officers, clearing agents and perhaps traders to declare any situations of conflict of interest. Three additional elements of a pro-integrity strategy could be a sound HR strategy based on clear rules for recruitment, promotion and separation, reasonable pay scales for customs officers (the existing remuneration schemes and levels may, however, significantly differ from one country to another), and a requirement for all customs staff to declare their assets on a regular basis.

SUGGESTED SHORT-TERM ACTIONS. Although reversing the situation can be lengthy and highly challenging, steps can be taken in the short-term. First, managers and supervisors should be required to carry out checks and internal inspections of customs operations on an ongoing basis and to report them periodically, in writing, to the head of customs. Second, a dedicated, and if possible independent body, should actively and promptly follow up on allegations of bribery, corruption and abuse of position.

26 See McLinden, G. Integrity in Customs in deWolf, L. and Sokol, J.B. (2005) Customs Modernization Handbook. The World Bank, Washington DC, USA.

27 See Durrani, A.Z, Prokop, M.A. \& Zarnowieki, M.R. Integrity Risk Modeling in the Border Management Context in McLinden, G, Fanta, E, Widdowson, D. and Doyle, T. (2011) Border Management Modernization. The World Bank. Washington, DC, USA. 


\title{
VI. CONCLUSION
}

The measures proposed in this note will require correct and complete application to produce significant revenue results. Like any reform, they can only be implemented with a strong commitment from country authorities and Customs management, a coherent plan of action, and monitoring of implementation. Technical assistance is also a critical factor of success and should be substantial, with a delivery adjusted to local absorption capacities, and an effective coordination of inputs where several donors are involved. For some measures proposed, some additional resources and limited legal changes may also be needed. In the context of fragile and low-income countries, these prerequisites are not always present. Nevertheless, there are currently, to varying degrees depending on the country and the functions concerned, many targeted initiatives in these countries that are consistent with the recommendations made in this note. Customs administrations have, in particular, launched initiatives to improve operations through the establishment of a national customs valuation service (for example, Mauritania, Burkina Faso), strengthening of customs transit monitoring (Benin, East Africa), or adoption of a clear framework for the customs clearance procedure. IMF TA, among others, has been supporting these reform initiatives. In most cases, these encouraging initiatives need to be finalized as soon as possible, ensuring that capacities, necessary means, notably in IT, and of course management of human resources and monitoring of performance and professional ethics, are simultaneously improved. Under these conditions, the administration will become more efficient in increasing revenue collections.

\section{ACRONYMS AND ABBREVIATIONS}

\author{
FAD ....... Fiscal Affairs Department \\ FZ ........ Free Zone \\ HS . . . . . . . Harmonized System \\ IMF . . . . . . International Monetary Fund \\ IT . . . . . . Information Technology \\ TA ....... . Technical Assistance \\ TIN. . . . . . Taxpayer Identification Number \\ VAT . . . . . . Value-Added Tax \\ WTO ...... World Trade Organization \\ wCo ...... World Customs Organization
}


This page intentionally left blank 